DOI: $10.17805 /$ trudy.2016.3.10

\title{
МЕЖДУНАРОДНАЯ НАУЧНАЯ КОНФЕРЕНЦИЯ «ЦИВИЛИЗАЦИОННАЯ ИДЕНТИЧНОСТЬ В СОВРЕМЕННОМ МИРЕ. ФИЛОСОФИЯ - КУЛЬТУРА - ПОЛИТИКА» (26-27 мая 2016 г., г. Москва)
}

\author{
А. В. Костина \\ (Московский гуманитарный университет)
}

Аннотация: В статье представлен обзор работы Международной научной конференции «Цивилизационная идентичность в современном мире. Философия - Культура - Политика», которая прошла в Московском гуманитарном университете 26-27 мая 2016 г.

Ключевые слова: Московский гуманитарный университет; идентичность; цивилизационная идентичность; культурология; обзор

\section{INTERNATIONAL CONFERENCE “CIVILIZATIONAL IDENTITY IN CONTEMPORARY WORLD. PHILOSOPHY. CULTURE. POLITICS” (Moscow, May 26-27, 2016)}

\author{
A. V. Kostina \\ (Moscow University for the Humanities)
}

Abstract: This is a review of the international research conference conference "Civilizational identity in contemporary world. Philosophy. Culture. Politics", which was held at Moscow University for the Humanities on May 26-27, 2016.

Keywords: Moscow University for the Humanities; identity; civilizational identity; culturology; review

26-27 мая 2016 г. в Московском гуманитарном университете прошла Международная научная конференция «Цивилизационная идентичность в современном мире. Философия - Культура - Политика», организованная кафедрой философии, культурологии и политологии МосГУ.

В конференции приняло участие около 120 человек из 40 организаций, среди которых - Московский гуманитарный университет, Российская академия наук, Международная академия наук, Институт философии РАН, Институт культурного и природного наследия им. Д. С. Лихачева, Московский государственный университет им. М. В. Ломоносова, Казахский уни- 
верситет им. Абылай хана (г. Алматы), Аналитический центр стратегических исследований «СОКОЛ», Государственный институт искусствознания, Российский государственный гуманитарный университет, Саратовский государственный университет им. Н. Г. Чернышевского, Институт проблем информатики РАН, МГТУ им. Н. Э. Баумана, Государственный университет «Дубна», Институт теории образования и педагогики РАО, Высшее театральное училище (институт) им. М. С. Щепкина, Российская академия народного хозяйства и государственной службы при Президенте РФ, Высшая школа экономики, Московский финансово-юридический университет, Московский городской педагогический университет, Научный совет РАН «История мировой культуры», Московский финансово-промышленный университет «Синергия», Научно-образовательное культурологическое общество, Национальный Союз негосударственных вузов.

К конференции выпущен сборник научных статей участников мероприятия (Цивилизационная идентичность ..., 2016). Среди 43-х авторов научных статей - В. М. Межуев, главный научный сотрудник Института философии РАН, действительный член Международной академии наук, доктор философских наук, профессор; И. В. Кондаков, профессор кафедры истории и теории культуры ОСКИ РГГУ, зам. Председателя Научного совета РАН «История мировой культуры», действительный член РАЕН доктор философских наук, кандидат филологических наук, А. Д. Урсул, профессор Московского государственного университета им. М. В. Ломоносова, доктор философских наук, профессор, Т. А. Урсул, профессор Национального исследовательского технологического университета «МИСиС», доктор философских наук, профессор, 3. С. Айдарбеков, заведующий кафедрой истории Казахстана и общественных наук КазУМОиМЯ им. Абылай хана. (г. Алматы), доктор философских наук, профессор, А. А. Горелов, доктор философских наук, ведущий научный сотрудник Института философии РАН, Н. Г. Багдасарьян, профессор МГТУ им. Н. Э. Баумана, зав кафедрой социологии и гуманитарных наук государственного университета «Дубна», доктор философских наук, профессор, Н. А. Хренов, главный научный сотрудник Сектора зрелищно-развлекательной культуры Государственного института искусствознания, доктор философских наук, профессор, О. А. Жукова, профессор философского факультета НИУ Высшая школа экономики (НИУ ВШЭ), доктор философских наук, кандидат культурологии, профессор, М. И. Козьякова, профессор кафедры философии и культурологии Высшего театрального училища (институт) им. М. С. Щепкина, Е. В. Листвина, зав. кафедрой философии культуры и культурологии Саратовского государственного университета им. Н. Г. Чернышевского, председатель Саратовского отделения НОКО, доктор философских наук, профессор; А. Я. Флиер, главный научный сотрудник Института куль- 
турного и природного наследия им. Д. С. Лихачева, доктор философских наук, профессор, О. Н. Астафьева, заместитель заведующего кафедрой ЮНЕСКО, директор Научно-образовательного центра «Гражданское общество и социальные коммуникации» Института государственной службы и управления РАНХиГС (Москва), доктор философских наук, професcop, А. А. Оганов, профессор Московского государственного университета им. М. В. Ломоносова, философского факультета, кафедры эстетики, зав. кафедрой прикладной культурологии и социокультурного менеджмента Высшего театрального училища (института) им. М. С. Щепкина, доктор философских наук, профессор, И. М. Быховская, профессор кафедры культурологии, социокультурной антропологии и социальных коммуникаций Российского государственного университета физической культуры, спорта, молодежи и туризма (РГУФКСМИТ), доктор философских наук, профессор, Л.А.Булавка-Бузгалина, профессор Московского финансовоюридического университета, доктор философских наук, профессор, И.Г.Хангельдиева, декан факультета «Предпринимательство в культуре», зав. кафедрой прикладной культурологии и социокультурного менеджмента Международного университета Москвы, профессор Московского государственного университета, факультета педагогического образования, кафедры истории и философии образования, доктор философских наук, профессор, Е. Н. Шапинская, заместитель руководителя экспертноаналитического Центра развития образовательных систем в сфере культуры Института культурного и природного наследия им. Д.С.Лихачева, доктор философских наук, профессор, С. Н. Гринченко, главный научный сотрудник Института проблем информатики Федерального исследовательского центра «Информатика и управление» РАН, доктор технических наук, профессор, академик МАИ, вице-президент Биокосмологической ассоциации от Европейской части Россиидоценты и профессора МосГУ, аспиранты, магистранты, студенты.

Модераторы конференции - Вал. А. Луков, директор Института фундаментальных и прикладных исследований Московского гуманитарного университета, заслуженный деятель науки РФ, действительный член Международной академии наук (IAS), доктор философских наук, професcop, А. В. Костина, заведующая кафедрой философии, культурологии и политологии Московского гуманитарного университета, действительный член Международной академии наук, доктор философских наук, доктор культурологии, профессор.

Тематика конференции была определена тем, что обострение «холодной» войны требует напряженной работы со стороны России и всех стран мира по выстраиванию в новых геополитических обстоятельствах неконфликтных, взаимовыгодных отношений, учитывающих цивилиза- 
ционные различия. Дискуссии и материалы публикаций показали, что цивилизация в современном мире выступает как основная геополитическая единица, более значимая, чем национальное государство. Это связано с тем, что в глобальном мире с глобальными процессами в области экономики, политики, науки, технологий, коммуникаций остается специфическим и не поддающимся универсализации то пространство, которое связано с ценностями, смыслами и целями цивилизации.

В ходе дискуссии было определено:

1. Цивилизацию продуктивно рассматривать не как множество эмпирических фиксируемых разных цивилизаций, а как единый процесс становления одной общей для всех и, следовательно, универсальной цивилизации, по отношению к которой все существующие на данный момент «цивилизации» предстают, как ее подготовительные фазы или ступени. Общим понятием цивилизации будет тогда не пустая абстракция, полученная путем сравнения разных цивилизаций, а мысленно фиксируемый результат, итог всего движения. В такой форме цивилизация и может быть понята как действительный антипод варварства;

2. Ценности как духовные сущности, выступающие основой любого цивилизационного кода, определяют и специфику ее материального, в том числе, экономического развития. Об этом сегодня говорят как западные, так и отечественные экономисты, отмечающие необходимость соответствия экономики и культуры как залога гармоничного развития страны. О неадекватности либеральной неоклассической парадигмы реальному экономическому развитию еще в 1971 г. как о причине финансового кризиса говорил президент Американской экономической ассоциации, лауреат Нобелевской премии В. Леонтьев, в 1972 г. этот тезис подтвердил Нобелевский лауреат Д. Тобин, в 1980 г. на этот факт обращал внимание классик теории экономического роста Р. Солоу. В последние годы проблеме необходимости соответствия практики управления хозяйством ценностям российской культуры уделяет значительное внимание академик С. Ю. Глазьев. Ученый выделяет следующие наиболее важные для развития российской экономики основания: необходимость помнить о духовном смысле жизни, заботиться о благе ближнего, общества и Отчизны; восприятие материального благополучия как испытания и ответственности; порядочность в деловых отношениях; необходимость творческого развития человека; необходимость заботы о человеке труда;

3. Глубинные причины обострения современной геополитической ситуации связаны не столько с известными экономическими проблемами, но, главным образом, с теми противоречиями в сфере культурных ценностей, которые характерны для стран Востока и Запада. Сегодня все мы являемся свидетелями беспрецедентного по своим масштабам и ожидаемым последствиям противостояния двух принципиально различных 
систем культурных ценностей, и именно это противоречие порождает целый комплекс весьма острых глобальных проблем дальнейшего развития цивилизации;

4. Цивилизационная идентичность Европы в начале XXI века разрушается. Одним из факторов ее расшатывания является международная миграция, масштабы которой существенно увеличиваются. Опасение усиления миграции, которое демонстрируют страны Европы, связано, в основном, с культурно-религиозным своеобразием народов Востока и Юга, которое может привести к разрушению европейского цивилизационного единства. То есть, конфликт между гражданами принимающей страны и гражданами страны-донора носит в большей степени культурный, а не экономический характер. Отсутствие в европейских странах внятной политики, направленной на включение мигрантов в новое для них цивилизационное пространство, обеспечение мигрантов правами, не сопровождающееся наделением их обязанностями по адаптации к принявшему их обществу и доминирующим здесь ценностям, восприятие даже тех из них, кто получает гражданство, как уже состоявшихся представителей своей страны - вне зависимости от усвоенности ими нового культурного кода - эти ошибки обернулись для Европы сегодня кризисом цивилизационной идентичности, справиться с которым будет весьма непросто;

5. Российская цивилизационная идентичность сохраняет свое ядро - Россия является цивилизацией, обладающей не только собственной спецификой, но и волей к ее развитию. Испытание ее цивилизационного кода на прочность осуществлялось неоднократно со времени Перестройки. Сначала это было испытание ценностями индивидуализма и достижительности, которые были присущи Евроатлантической цивилизации, доказавшей в тот период свое экономическое превосходство. Одновременно - это было испытание ценностями либерализма, под знаменем которых осуществлялся развал Советского Союза. Отпадение стран - бывших союзных республик - означало необходимость для России поиска обновленных оснований для идентификации. Таким же испытанием для России стали события в Украине. Оранжевая революция и Евромайдан, трагические события в Одессе и Донбассе показали, что код цивилизационной идентичности может быть сильно трансформирован, и есть специальные технологии, прежде всего, информационной войны, направленные на эффективное его разрушение;

6. Россия сегодня - великая страна, сохранившая после многочисленных испытаний последних десятилетий свой цивилизационный код. Это страна с восстановленным чувством гордости за свою историю, пережившая комплекс своей вины за трагические события, связанные с репрессиями и осознавшая их как величайшую трагедию и как то, что никогда не 
должно повториться. Это страна, победившая во Второй мировой войне и ставшая страной-освободительницей для многих европейских государств и народов, сохраняющая память об этих событиях и испытывающая гордость за тех, кто остается с нами в Бессмертном Полку. Сегодня Россия - страна, восстановившая не только историческую справедливость, но и цивилизационное единство в акте воссоединения Крыма с Россией. Это сильное государство, способное оказать помощь нуждающимся в ней странам, ставших заложниками «национальных интересов Америки», проявившихся за тысячи километров от границ США - в Сирии, Ираке, Иране. Сегодня Россия - открытая для граждан других государств страна, приезжающим сюда в качестве туристов, временных или постоянных мигрантов.

Участники конференции также пришли к выводу, что для сохранения цивилизационной идентичности России необходимо:

•укрепление гражданственности, патриотизма, социальной солидарности, сплоченности российского народа,

- укрепление экономического и оборонного потенциала страны;

- обеспечение национального единства страны и мобилизации всех интеллектуальных и духовных ресурсов народов России,

- формированиеусловийдлясоздания высокихдуховно-нравственных и эстетических ценностей на основе традиций и достижений профессионального искусства,

•поиск корректных инструментов регулирования информационной среды, прежде всего, ресурсами культуры.

\section{СПИСОК ЛИТЕРАТУРЫ}

Цивилизационная идентичность в современном мире. Философия Культура - Политика (2016) : сб. науч. трудов / под ред. А. В. Костиной. М.: РУСАЙНС. 266 с.

Костина Анна Владимировна - доктор философских наук, доктор культурологии, декан факультета философии, культуры и искусства, заведующая кафедрой философии, культурологии и политологии Московского гуманитарного университета. Адрес: 111395, Россия, г. Москва, ул. Юности, д. 5. Тел.: +7 (499) 374-61-81. Эл. адрес: anna_kostina@inbox.ru

Kostina Anna Vladimirovna, Doctor of Philosophy, Doctor of Culturology, Professor and Dean, Faculty of Philosophy, Culture and Arts; Chair, Department of Philosophy, Culturology and Politology, Moscow University for the Humanities. Postal address: 5 Yunosti St., 111395 Moscow, Russian Federation. Tel.: +7 (499) 374-61-81. E-mail: anna_kostina@inbox.ru 


\title{
ВЫШЛА В СВЕТ НАУЧНАЯ МОНОГРАФИЯ «ДРАМАТУРГИЯ А. С. ПУШКИНА: ПРОБЛЕМА СЦЕНИЧНОСТИ»
}

\author{
Б. Н. Гайдин \\ (Московский гуманитарный университет)
}

Аннотация: В статье анонсируется издание 2015 года - коллективная научная монография «Драматургия А. С. Пушкина: проблема сиеничности» (авторы - Н. В. Захаров, Вал. А. Луков, Вл. А. Луков).

Ключевые слова: аннотация; издание; А. С. Пушкин; тезаурусный подход; Московский гуманитарный университет; проблема сценичности

\section{“A.S. PUSHKIN'S DRAMATIC ART: THE PROBLEM OF STAGINESS": A NEW MONOGRAPH}

\author{
B. N. Gaydin \\ (Moscow University for the Humanities)
}

\begin{abstract}
This short piece announces the publication of a collective monograph “A.S. Pushkin's Dramatic Art: The Problem of Staginess" (2015) which presents the outcomes of a Russian Foundation for the Humanities-supported project. The book was edited by N.V. Zakharov, Val.A. Lukov, Vl.A. Lukov.

Keywords: blurb; monograph; A.S. Pushkin; thesaurus approach; Moscow University for the Humanities; problem of staginess
\end{abstract}

24 июня 2016 г. в рамках научной сессии Института фундаментальных и прикладных исследований Московского гуманитарного университета «Улучшение человека: современные философские концепции» состоялась презентация коллективной научной монографии «Драматургия А.С.Пушкина: проблема сценичности» (Захаров, Луков Вал., Луков В., 2015). Монография вышла в издательстве Московского гуманитарного университета в 2015 г.

В монографии анализируется парадоксальная «несценическая» сценичность драматургии А. С. Пушкина. Применяя методологию тезаурусного подхода, авторы монографии показывают, как через осознание шекспиризма Пушкин открыл новую сценичность, которая выходит за пределы традиционной театральной сценичности и может рассматриваться как феномен русской культуры. 